BNL-82182-2009-CP

\title{
Four Critical Needs to Change the Hydrate Energy Paridigm from Assessment to Production: The 2007 Report to Congress by the U.S. Federal Methane Hydrate Advisory Committee
}

D. Sloan, P. Brewer, N. Dutta, A. Johnson, E. Jones, K. Juenger, M. Kastner, D. Mahajan, S. Masutani, R. Swenson, J. Whelan, S. Wilson, R. Woolsey

Presented at Offshore Technology Conference 2008

May 2008

Energy Science and Technology Department/Energy Resources Division

Brookhaven National Laboratory

P.O. Box 5000

Upton, NY 11973-5000

www.bnl.gov

Notice: This manuscript has been authored by employees of Brookhaven Science Associates, LLC under Contract No. DE-AC02-98CH10886 with the U.S. Department of Energy. The publisher by accepting the manuscript for publication acknowledges that the United States Government retains a non-exclusive, paid-up, irrevocable, world-wide license to publish or reproduce the published form of this manuscript, or allow others to do so, for United States Government purposes. 


\section{DISCLAIMER}

This report was prepared as an account of work sponsored by an agency of the United States Government. Neither the United States Government nor any agency thereof, nor any of their employees, nor any of their contractors, subcontractors, or their employees, makes any warranty, express or implied, or assumes any legal liability or responsibility for the accuracy, completeness, or any third party's use or the results of such use of any information, apparatus, product, or process disclosed, or represents that its use would not infringe privately owned rights. Reference herein to any specific commercial product, process, or service by trade name, trademark, manufacturer, or otherwise, does not necessarily constitute or imply its endorsement, recommendation, or favoring by the United States Government or any agency thereof or its contractors or subcontractors. The views and opinions of authors expressed herein do not necessarily state or reflect those of the United States Government or any agency thereof. 
Offshore Technology Conference 2008 (OTC08)

Houston, TX

May 5-8, 2008

OTC Paper Number: OTC-19519-PP 


\title{
OTC Paper Number: OTC-19519-PP
}

\section{Four Critical Needs to Change the Hydrate Energy Paradigm from Assessment to Production: The 2007 Report to Congress by the U.S. Federal Methane Hydrate Advisory Committee}

\author{
Dendy Sloan, SPE, Colorado School of Mines; Peter Brewer, Monterey Bay Aquarium Research Institute;, \\ Richard Charter Defenders of Wildlife; Nader Dutta, SPE, Schlumberger; Arthur Johnson, Hydrate Energy \\ International,, Emrys Jones, SPE, Chevron Petroleum Technology, Kimberly Juenger, World Energy Systems: \\ Miriam Kastner, Scripps Institute; Devinder Mahajan, Brookhaven National Laboratory; Stephen Masutani, \\ University of Hawaii; Robert Swenson, State of Alaska; Jean Whelan, Woods Hole Oceanographic Institute, Scott \\ Wilson, SPE, Ryder Scott, Inc.; Robert Woolsey, University of Mississippi \\ Copyright 2008, Offshore Technology Conference
}

This paper was prepared for presentation at the 2008 Offshore Technology Conference held in Houston, Texas, U.S.A., 5-8 May 2008.

This paper was selected for presentation by an OTC program committee following review of information contained in an abstract submitted by the author(s). Contents of the paper have not been reviewed by the Offshore Technology Conference and are subject to correction by the author(s). The material does not necessarily reflect any position of the Offshore Technology Conference, its officers, or members. Electronic reproduction, distribution, or storage of any part of this paper without the written consent of the Offshore Technology Conference is prohibited. Permission to reproduce in print is restricted to an abstract of not more than 300 words; illustrations may not be copied. The abstract must contain conspicuous acknowledgment of OTC copyright.

\begin{abstract}
This work summarizes a two-year study by the U.S. Federal Methane Hydrate Advisory Committee recommending the future needs for federally-supported hydrate research. The Report was submitted to the US Congress on August 14, 2007 and includes four recommendations regarding (a) permafrost hydrate production testing, (b) marine hydrate viability assessment (c) climate effect of hydrates, and (d) international cooperation.
\end{abstract}

\section{Introduction}

A secure supply of natural gas is a vital goal of the U.S. national energy policy because natural gas is the cleanest and most widely used of all fossil fuels. The inherent cleanliness of natural gas, with the lowest $\mathrm{CO}_{2}$ emission per unit of heat energy of any fossil fuel, means substituting gas for coal and fuel oil will reduce emissions that can exacerbate the greenhouse effect. Both a fuel and a feedstock, a secure and reasonably priced supply of natural gas is important to industry, electric power generators, large and small commercial enterprises, and homeowners.

Because each volume of solid gas hydrate contains as much as 164 standard volumes of methane, hydrates can be viewed as a concentrated form of natural gas equivalent to compressed gas but less concentrated than liquefied natural gas (LNG). Natural hydrate accumulations worldwide are estimated to contain 700,000 TCF of natural gas, of which 200,000 TCF are located within the United States. Compared with the current national annual consumption of 22 TCF, this estimate of in-place gas in enormous. Clearly, if only a fraction of the hydrated methane is recoverable, hydrates could constitute a substantial component of the future energy portfolio of the Nation (Figure 1). However, recovery poses a major technical and commercial challenge.

Such numbers have sparked interest in natural gas hydrates as a potential, long-term source of energy, as well as concerns about any potential impact the release of methane from hydrates might have on the environment. Energy-hungry countries such as India and Japan are outspending the United States on hydrate science and engineering R\&D by a factor of 10 , and may bring this resource to market as much as a decade before the United States. 


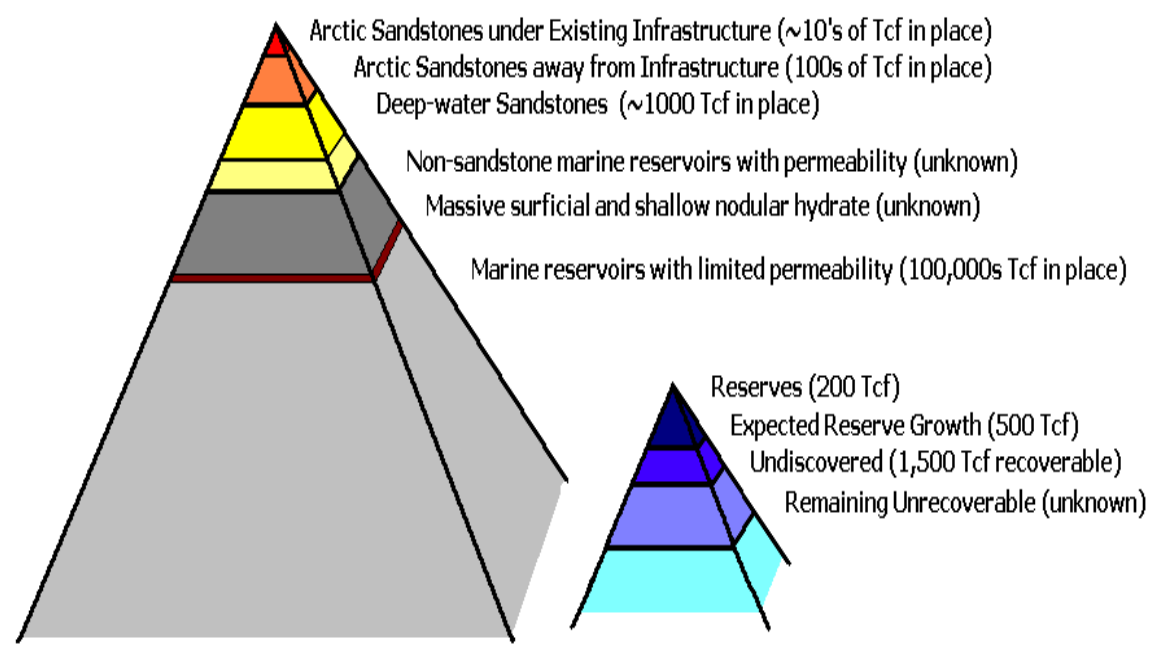

Figure 1. Hydrate resource (left) relative to the conventional natural gas resource (right) for the United States.

With the potential of such a substantial energy resource at hand, the question arises as to why U.S. energy companies have not actively pursued hydrate exploration and recovery. The answer lies in the fact that, at present, ample global supplies of conventional natural gas at economically attractive prices allow the United States to meet its energy needs with a mix of domestically produced gas and gas imported from Canada and from overseas in the form of LNG. Furthermore, given the significant technological challenges of locating and producing gas from methane hydrate accumulations, its economic viability is currently beyond the energy industry's horizon for financial consideration.

For example, at a meeting on March 16, 2007, managers from BP, ConocoPhillips, Chevron, ExxonMobil, and Shell independently offered these opinions about the hydrate resource:

- "Hydrates as a resource are too far out to be viably economically recoverable. We need government funding and leadership to establish needed science and engineering."

- "Unless cost incentives are improved, hydrates in nature may remain untapped, awaiting excessive oil prices to become feasible."

- $\quad$ Our company critically evaluated work by Moridis, Collett, and Dallimore (acknowledged hydrates-in-nature experts). The conclusion was that natural gas hydrates ranked below all other hydrocarbon resources with regard to commercial value in the next decade."

- "U.S. science and engineering significantly lag behind international government efforts."

- "This effort needs leadership which will not be provided by the energy industry."

These statements demonstrate that the energy industry is unlikely to focus resources in the near-term on developing gas hydrates, because hydrates are not expected to be economically viable in the next decade.

There are, however, several reasons why the Federal government should take the lead in this endeavor:

1. The science is new, and the occurrences of natural hydrates are complex and not yet well understood, leading to the need for substantial investments in basic science, data gathering, and theoretical validation—areas an industry focused on short-term returns is unlikely to finance;

2. Research in gas hydrate science requires specialized technologies, both to recreate hydrates in the laboratory and to study them in arctic or deepwater marine environments, and these technologies are expensive;

3. While the ultimate outcome of these investments is uncertain, the long-term potential benefit to the Nation is enormous, exactly the sort of high-risk/high-reward R\&D where Federal funding has historically generated large public benefits.

This Committee believes that hydrate research and development investments now will generate significant benefits in future domestic energy supply. As leaders of the world's technological community, and as an energy-dependent nation, it is incumbent on the United States to increase funding for the development of this long-range energy source. 


\section{State-of-the-Art, and the Shortfalls in Hydrate Science}

Hydrate developmental strategy is influenced by two facts:

1. The total amount of hydrates in the marine sediments is several orders of magnitude greater than the amount of hydrates in permafrost.

2. Hydrates in the permafrost often have the advantage of occurring in higher concentrations than in seafloor sediments and in several readily-accessible U.S. locations.

As a consequence, U.S. hydrates are first being accessed for exploration and production testing in the North Slope, Alaska, region permafrost. Technology transfer will then extend from these permafrost hydrates to the development of marine hydrates. The first U.S.-led effort to test hydrate exploration technology at Milne Point on Alaska's North Slope took place early in 2007.

However, the lead in hydrate science and technology is rapidly being taken by pioneers such as India and Japan, which are rapidly being followed by China and South Korea. Unless the United States increases its investment in hydrates, it will have to be satisfied with an "early-settler" role, rather than as a pioneer-hoping that knowledge developed by other countries will be made available. This "wait-and-adopt" strategy also relegates the United States to second place status in the pursuit of potentially valuable technology patents, and precludes the United States from establishing early standards to ensure that hydrate resources are accessed in a safe and environmentally responsible manner.

For example, Japan sponsored the first proof-of-concept hydrate energy recovery wells in the Canadian Arctic (the Mallik project). This project began in 1998 and culminated in a production test. Japanese hydrate R\&D expenditures were in excess of US\$100 million in 2003, and US\$68.5 million was spent on research in the Sea of Kumano off Japan alone during 20062007. The Japanese government has set a goal of commercial methane gas production from hydrates by 2017. It is estimated that Japan’s production test well program at Mallik will cost in excess of Can $\$ 75$ million. Beyond Japan’s aggressive program, a 113-day Indian hydrate ocean expedition was undertaken during 2006 at a cost of US\$36million. India’s plans include a commitment for a production test well by 2009.

In contrast, Federal government hydrate research expenditures have averaged $\sim \$ 10$ million per year since 2001, and the first U.S. exploratory test well (an arctic test rather than a marine test) was drilled in February 2007. If funding levels are not increased, as recommended by this Committee, U.S. ocean hydrate production will not occur until substantially after production is realized in India and Japan.

The Committee has identified four principal R\&D shortfalls related to hydrate development.

\section{A Long-Term Production Test Well for Arctic Hydrate Assessment}

For an understanding of the potential of permafrost hydrates, a long-term production test well is needed to enable the testing of various recovery strategies and to provide for modeling verification.

Currently, there is no commercially proven way to recover methane gas from hydrates in permafrost, the most easily accessible location where hydrate is found. The gas from these hydrates is potentially producible today, given a pipeline or nearby commercial use for the gas. The Japanese performed a three-week well test at the Mallik site in Canada during the winter of 2006-2007, and DOE plans a similar production test on the Alaskan North Slope during the winter of 2007-2008, assuming sufficient funding.

Computer reservoir models are critical tools for the economic development of any conventional gas field. Hydrate reservoir models exist (e.g. TOUGH+Hydrate, STOMP, CMG-STARS, etc.), and they are currently being tested against each other to assess their reproducibility in the simulation of methane production from idealized hydrate reservoirs. However, the accuracy of these models can be verified only against data from a long-range, quasi-steady-state production test, with a minimum of the transient phenomena that can obscure observations of true reservoir behavior.

Hydrates can be decomposed to release trapped methane by reducing the ambient pressure, by heating to raise the ambient temperature, or by exposure to freezing-point reducers (anti-freezes) such as methanol. While there is no standard, proven method of hydrated gas production, it is believed that simple depressurization may cost less than thermal stimulation or inhibitor injection strategies. Prudent combinations of two or more of these approaches may be needed. In addition, other 
innovative techniques, such as geothermal stimulation or controlled oxidation, have yet to be attempted. A long-term, Alaskan Arctic testing facility could be constructed relatively inexpensively at a gravel pad on the North Slope of Alaska and would provide an opportunity to explore recovery techniques suitable for the permafrost. The results of such tests of permafrost technology (e.g., hydraulics, geomechanics, heat transfer, etc.) might then be transferable to inform the development of marine hydrate recovery techniques.

\section{Assessment of the Economic Viability of Marine Hydrate Deposits}

Because most of the US hydrate deposit is in the ocean, there is a need for the assessment of the economic viability of hydrate production. A principal need to assess the amount of marine hydrates is a requirement for remote sensing tools that can reliably locate and characterize gas hydrate deposits, as integral steps to assess the economic viability of the marine hydrate energy resource. An early remote sensing approach—using geophysics to search for what was believed to be seismic indicators of hydrate accumulations (bottom simulating reflectors, or BSRs)—has proven unreliable. A BSR is a subsurface reflection that appears on seismic cross-sections and parallels the sea bottom while crossing sedimentary boundaries, as an accumulation of hydrate might do.

Some large-scale hydrates discoveries have been made without any evidence of a BSR, and at the same time BSRs have been located, tested, and found to be devoid of hydrates. Two illustrations confirm this point. While the 113-day Indian hydrate expedition in 2006 drilled 22 sites where BSRs were detected, at one site off the west coast of India it was discovered that the BSR was in fact caused by a calcium carbonate deposit rather than hydrates. ${ }^{1}$ Another example is the group of giant hydrate mounds found on the seafloor in Barkley Canyon west of Vancouver, BC. Here, seismic signals indicated that these hydrate deposits, with thin sediment cover, appeared geophysically equivalent to ocean bottom sand. ${ }^{2}$

In the future the BSR will likely be coupled with a suite of remote detection methods, as has been noted by Mahajan and Somasundaran: "A thorough and cost-effective preliminary survey site protocol needs to be developed to include geochemical, heat flow, and electromagnetic characterization of deepwater-sediment hydrate beds. These data will be coupled with seismic surveys to determine deep drilling locations. ${ }^{3}$

The program is currently pursuing a number of other hydrate detection technologies, some of which were validated by the successful drilling of the Mt. Elbert test well in Alaska during February 2007. However, the need for remote sensing hydrate tools that can reliably locate gas hydrate deposits is a critical one.

\section{Understanding the Role of Hydrates in the Environment}

The exact nature of what appears to be a dynamic relationship between methane hydrates and the environment remains a significant unknown. The most recent review of hydrate in the environment states, "The methane contribution from hydrate decomposition is an important unknown in the global methane budget."

In their controversial book, Methane Hydrates and Quaternary Climate Change: The Clathrate Gun Hypothesis, Kennett, et al., suggest that as recently as the Late Quaternary Period (15,000 years ago) hydrates contributed to the greenhouse warming effect. $^{5}$ There is a scientific community consensus that this hypothesis, reviewed in this Committee's 2004 Report to Congress, requires substantial verification via research before it can advance to the state of being a reliable theory.

There is substantial evidence within the isotopic fossil record of massive methane release, probably from hydrates 5 million years ago, at the Last Paleocene Thermal Maximum, which caused warming of the earth by as much as $8{ }^{\circ} \mathrm{C}^{6}$ Verifying the role of methane hydrates in global climate change is critical because of the fact that methane has a greenhouse warming potential 21 times that of $\mathrm{CO}_{2}$. A better understanding of the pivotal role that hydrates might play in the global climate could influence U.S. policy choices related to global warming mitigation decisions.

A second important aspect of the relationship between hydrates and the environment concerns seafloor stability. In the last few decades, energy companies have grown increasingly concerned about the impact of hydrates on seafloor stability, particularly as development activities have ventured further into deeper waters. Destabilization of hydrates in seafloor 
sediments may cause underwater landslides or sediment fluidization that can jeopardize offshore oil production facilities. A possible example of this is shown in Figure 2, which displays a seismic cross-section from the Blake-Bahama Ridge off the southeastern coast of the United States. In this example, the seismic line reflection that is appears parallel to (but is deeper than) the mudline - the so-called BSR — is seen to be absent under the area exhibiting evidence of disrupted sediment. This could be interpreted as providing evidence of methane evolution from a hydrate accumulation and an associated disruption of the sediments above as methane is released into the ocean.

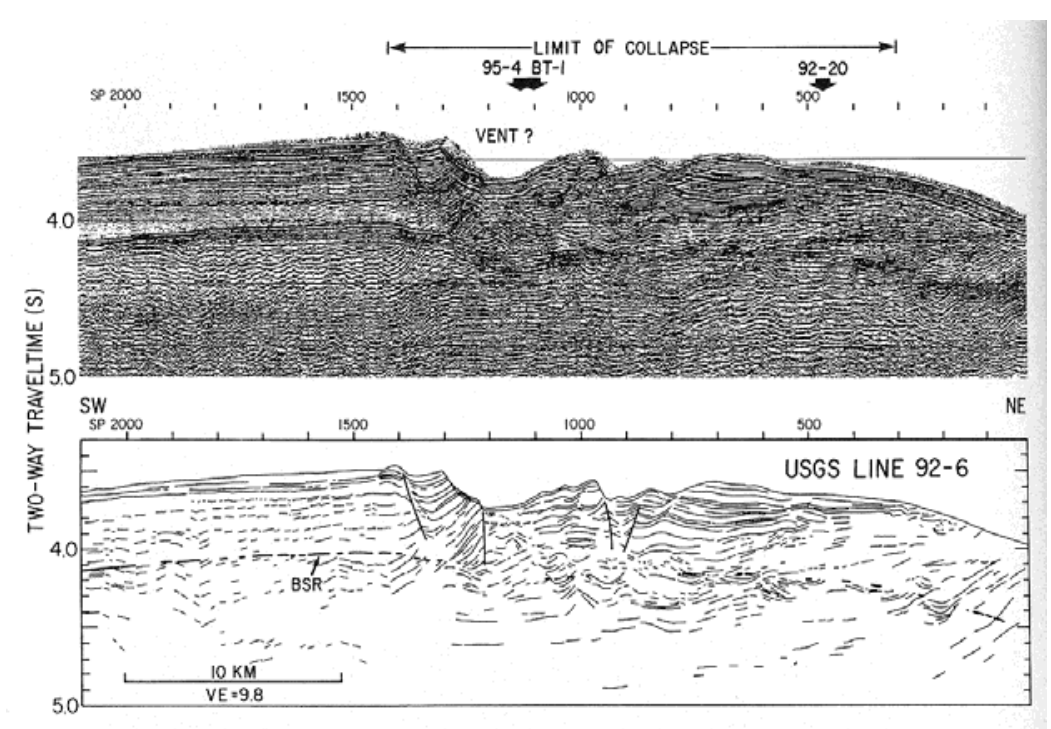

Figure 2. Hydrate disruption below the seafloor at the Blake-Bahama Ridge (Dillon, et al., Natural Gas Hydrates: Occurrence, Distribution and Detection, Dillon and Paull, eds., American Geophysical Union, p. 218, 2001). The bottom image is a cartoon of the seismic section. Note the disruption in the middle of the diagram, between the mudline and the BSR, indicating gas evolution.

\section{Enhancing International Cooperation}

Because (a) many nations will benefit, and (b) the exploration of this resource is so expensive, international cooperation rather than competition should advance our understanding and exploration of hydrates in nature. The combination of knowledge, experience, resources, and motivation are all central to this effort. Two recent examples of successful international cooperation are the Mallik2002 well and the 2006 Indian Natural Gas Hydrate Expedition.

The two major accomplishments of Mallik 2002 were: 1.Gas was immediately produced from hydrates via controlled depressurization and thermal stimulation tests, without question regarding the gas source and 2) data were obtained to calibrate well logs and gas hydrate production simulators.

The above two accomplishments provide a hallmark in the knowledge development of hydrates in nature. It is now beyond question that gas can be produced from hydrates, and that data from such production can be accurately modeled. However, because only a few days were spent proving the concept, the transient results prevented the unambiguous long-term modeling of hydrate production, as shown in the sections which follow. As one result of this work, it appears to be important to provide a longer production test, to enable the long-term projection of gas production from hydrates.

Similarly, international cooperation was a hallmark of the 2006 Indian Natural Gas Hydrate Expedition, which discovered and sampled the richest marine hydrate accumulation to date. In addition to the technical accomplishments in the Indian cruise, over 40 hydrate scientists were trained for future study of hydrates in nature. This expedition is a principal exemplar of the combination of motivation, resources, knowledge, and experience to bring a large project to a timely and successful conclusion.

\section{Conclusion}

With the transition of the hydrates in nature paradigm from exploration to production, there are four needs which could significantly further the state-of-the-art:

1. a long term production test is needed for hydrates in the permafrost,

2. it is needed to determine whether marine hydrates are economically viable,

3. the role of hydrates needs to be established for the environment, and 
4. international cooperation is required for economy of knowledge, time, and expense.

\section{References}

${ }^{1}$ T. Collett, personal communication to E.D. Sloan, February 27, 2007.

${ }^{2}$ P.Brewer, personal communication to Sloan, March 22, 2007.

${ }^{3}$ Science and Technology Issues in Methane Hydrate R\&D, 2006 Engineering Conferences International, D. Mahajan and P. Somasundaran, Eds., March 2007.

${ }^{4}$ W.S. Reeburgh, Chem. Reviews, vol 107(2), 486-513, 2007, doi:10;1021/cr050362v.

${ }^{5}$ Kennett, et al., Methane Hydrates and Quaternary Climate Change: The Clathrate Gun Hypothesis, AGU, 2003.

${ }^{6}$ Dickens, Science, 299, 1017, 2003. 